CANADA

\section{Water and Climate Studies in Canada using Isotope Tracers: Past, Present, Fułure}

31 st January and 1st February 1997,

Waterloo, Canada

Report of the workshop

This two-day workshop was convened with the twin aims of reviewing the state of water and climate research in Canada using isotope tracers and investigating the establishment of a revitalized "Canadian Network for Isotopes in Precipitation", as a contribution to the international GNIP program (Global Network for Isotopes in Precipitation), which is the well-known offspring of long-standing IAEA/WMO efforts to document the distribution of water isotopes in the global water cycle. About 60 participants from university, government, and the private sector gathered for two days of presentations and discussions at the University of Waterloo, Ontario, Canada.

The workshop was sponsored by Environment Canada, through the Atmospheric Environment Service (Downsview, Ontario) and the National Hydrology Research Institute (Saskatoon, Saskatchewan), with additional support from the Canadian Geophysical Union, the Waterloo Centre for Groundwater Research, and several other Waterloo-based university research bodies.

Background on international GNIP activities, the PAGES perspective, and comments on experience gained from national isotope networks in Switzerland and Germany were provided in Plenary Lectures from, Klaus Froehlich (IAEA) and Ulrich Schotterer (PAGES). Special guests Emi Ito (University of Minnesota) and Carol Kendall (US Geological Survey) offered narrative on the current situation in USA regarding potential for developing a national precipitation network and the existing USGS isotopic data base from surface waters. Subsequent presentations were selected to sample the broad spectrum of past and present activities in Canada, falling into three general areas: assessment of existing isotopic data from past and ongoing precipitation sampling in Canada and efforts to define the nature of isotope-climate linkages; atmospheric studies, including discussion of carbon and oxygen stable-isotope signals in atmospheric carbon dioxide and links with the water cycle; and the use of isotope tracers in hydrologic, paleohydrologic, and ecologic studies of surface and ground waters, groundice, and the water isotope records preserved in other archives.

The presentations demonstrated clearly that substantial Canadian expertise exists in this field, complemented by the capacity and willingness to train young researchers. The discussions also led to consensus that an ex- panded network of 20-30 meteorological stations collecting monthly-composite precipitation samples for isotopic analysis was desirable and feasible, building on the network of sites in Canada currently contributing data to GNIP. The existing "CNIP" includes Ottawa (1953-present) and eight northern stations (1989-present), plus data in the GNIP archive from previous monthly-composite sampling campaigns at a number of other sites in the 1970 s and 1980s. Various targeted research projects, including ongoing event-based precipitation sampling in Winnipeg (1992present), have also generated abundant data that are not yet formally archived. A revitalized CNIP would constitute a valuable Canadian contribution to international water and climate studies, as well as providing a framework for nested campaigns requiring more intensive temporal or spatial sampling, such as the Mackenzie Basin Study of the Global Energy and Water Cycle Experiment (GEWEX-MAGS).

The workshop culminated in a provisional agreement to work towards the establishment of a rejuvenated and expanded CNIP, based on a model in which responsibilities for sample collection and analysis would lie, respectively, with the Atmospheric Environment Service of Environment Canada and a consortium of university and government isotope laboratories. A special sub-committee of the Committee on Isotope Tracer Techniques within the Hydrology Section of the Canadian Geophysical Union will assume responsibility for overall scientific direction and administration, and the continuity of the program.

Aspects of the challenges and opportunities associated with CNIP will also be addressed at the upcoming annual meeting of the Canadian Geophysical Union (Banff, 4-9 May 1997) and the ISOBALANCE International Workshop on Application of Stable Isotopes in Water Balance Studies (Saskatoon, 1418 July 1997).

Further information about the CNIP Workshop and ongoing activities can be obtained through:

\section{Thomas W.D. EdWARds}

Associate Professor Dept of Earth Sciences

University of Waterloo

200, University Avenue West

Waterloo, ON N2L 3G1, CANADA

Phone: + 15198884567 ext 3236

Fax: +15197460183

e-mail: twdedwar@uwaterloo.ca
GERMANY

Cooperative Research

Project "ACACIA"

(Arid Climate, Adaptation and Cultural Innovation in Africa) 1995-2010

This long term research initiative in Germany contains several sub-projects of interest to PAGES. Three of these are described briefly below.

Further information can be obtained from the project leaders through Stefan Kroepelin.

\section{CLIMATIC CHANGE AND HUMAN SETTLEMENT BETWEEN THE NILE VALLEY AND THE CENTRAL SAHARA}

In follow-up to the long-term interdisciplinary project, "B.O.S." (Settlement History of the Eastern Sahara; 1980-1995) further and more detailed research will be conducted in the Northern Libyan Desert. This sub-project focuses on the initial stages and spread of food-producing economies, the general question regarding the mono- or polycentric development of Neolithic phenomena, and the relevance of these processes to the birth and rise of Egyptian civilization.

Since the ecological setting for human activity in this region can be divided into three larger environmental zones - the summer rains in the North, winter rains in the South, and the Nile Valley in the East - the study of regional climatic development is a necessary prerequisite for understanding the historical development and the possible role and range of interregional contacts. Therefore, a detailed regional chronology must be determined based on geomorphological / sedimentological analyses as well as archaeological excavations, which take into consideration palaeobotanical and archaeo-zoological aspects.

Within the general framework of the Cooperative Research Project - man and his environment - this sub-project focuses on the earliest indications of the interdependence between socioeconomic development and environmental conditions, investigates the transition to a productive economy, and therefore endeavours to record the initial stages of cultural change, which apparently began in the north of the continent and following a few millennia would later affect the south. 